\title{
Interior Materials Combination and Perceived Indoor Air Quality
}

\author{
Ingrid Juhasova Senitkova, ${ }^{1, *}$ \\ ${ }^{1}$ Institute of Technology and Business in České Budějovice, Department of Civil Engineering, \\ Okružní 517/10, 37001 České Budějovice Czech Republic
}

\begin{abstract}
The materials used in the buildings, either as surface structural materials or as furnishings, are mostly the sources of indoor air pollution. Interior surfaces are generally accepted as the main source of indoor TVOCs emissions. The poor indoor microclimate quality can cause the sick building syndrome, as well as negatively affects the people activities and wellbeing. In recent years the needs of indoor air quality and building performance improvement have been increasing. The indoor materials impact on perceived indoor air quality for various surface interior materials and its combination was studied within this paper. Traditional and progressive materials comparison reveals new fact regarding the TVOCs concentration. The task of the study was to investigate the possibility using individual material surfaces sorption ability. The chemical analysis and sensory assessments identifies health adverse of indoor air pollutants (TVOCs). Also we can use knowledge about the targeted use of sorption effect already in the building design phase. The results demonstrate the various sorption abilities of various indoor materials as well as various sorption ability of the same indoor material in various combinations.
\end{abstract}

\section{Introduction}

Even all indoor environmental standards are met the users are usually not satisfied and perceived discomfort is occurred in the smart buildings. The most frequently cause of discomfort in smart buildings is overrun of intelligence. There are physical and psychological factors that influenced building users' comfort. Poor indoor air quality is believed to be responsible for a substantial part of the sick building syndrome that has been reported, but the indoor environment is extremely complex and other factors also undoubtedly contribute to the problem. Provided an environmental and economic will within our society will became aware of the real needs of solving the healthy buildings problem - we are able to offer the models and strategies the tools, and criteria, and finally the construction technology and an architectural idiom to design, to build, and to maintain sustainable buildings on short and long term as well as affordable. A health impact assessment and an environment impact assessment are needed to judge the real quality of a building and particularly indoor design [1].

\footnotetext{
*Corresponding author: 14667@mail.vstecb.cz
} 
Many of the materials used in buildings, either as interior materials or as furnishings, are the main sources of indoor air pollution in addition to those caused by humans and their activities and HVAC systems. The important source is the indoor surface materials of building itself, which in many cases can result in great amount of indoor volatile organic compounds (VOCs). It is especially building material finishes (floors, walls and ceilings) which are considered to have an important role also of perceived indoor air quality [1,2]. The research project is focused to indoor air sciences, especially to perceived air quality observation focused on selected chemicals occurrence in public buildings have shown that mainly office buildings have high level of pollution related to interior materials $[2,3]$. Many of the materials used in buildings, either as interior materials or as furnishings, are the main sources of indoor air pollution in addition to those caused by humans and their activities and HVAC systems. The important source is the indoor surface materials of building itself, which in many cases can result in great amount of indoor volatile organic compounds (VOCs).

It is especially building material finishes (floors, walls and ceilings) which are considered to have an important role also of perceived indoor air quality. The ability to accurately evaluate volatile organic compound (VOC) emissions from indoor materials requires reliable and consistent chamber tests. The principle of the test method is to assess the emission of pollutants from a test specimen, prepared from a sample of a building material, by sensory assessments and concentration measurements of the air in a test chamber. The surface of the test specimen is exposed to the chamber air which is maintained at a temperature, humidity and air change similar to that which can be expected in the indoor environment in which the material is usually used. In addition to these conditions the chamber concentration depends on the supply airflow rate in the chamber and the area of the test specimen. The test should be performed with an area specific airflow rate similar to that which can be expected during the normal use of the material.

However, previous chamber comparisons show significant variations among laboratory testing results $[4,5]$. One means of addressing these inconsistencies is by using a reference material with an independently known emission rate to evaluate the performance of a laboratory emission chamber. Previous tests have also shown that a chamber's environmental conditions of temperature and relative humidity have the potential to influence the emission of certain VOCs from building materials. Thus, if a chamber is not operating at the specified environmental set-points for a test, the emission rate results could vary. The research on the impact of indoor air conditions; temperature, relative humidity and surface air velocity on materials emission rates were done. The results indicate that both the temperature and relative humidity have a significant effect on the emissions from paint and varnish. In the case of varnish, the results were consistent with earlier results. However, the paint results show inconsistent emission behaviour. Further, for both materials, the individual compounds did not necessarily follow the same trend established for the TVOC $[6,7]$.

\section{Experimental program}

The TVOCs and odors emissions from various indoor surface materials were studied. OSB boards, HDF laminate flooring, Polyamide carpet, PVC, Cork, Terazzo, Cotton carpet, Marmoleum, Wooden parquet, LG Hi-macs and Corian were investigated as typical flooring covering. Painted gypsum boards as wall and ceiling coating material were used for studied combinations. The individual materials and their combinations (C1-C11) are shown in the Table 1. The TVOCs and odors emissions from these common indoor surface materials as well as their combination were investigated in test chamber under the standardized condition $\left(22-24^{\circ} \mathrm{C}, 40-60 \%, \mathrm{v}=0.1-0.2 \mathrm{~m} / \mathrm{s}\right.$ and air change rate $\mathrm{n}=0.5$ 
1/h). Chemical measurements (TVOC) and sensory assessments (odor intensity, perceived air quality) were done after building materials exposure to standardized conditions. The necessity of parallel chemical and sensory analysis of indoor air quality was confirmed. On the base of the results it is possible to assume that human nose is much more sensitive than chemical testing procedures. Both, parallel used methods, chemical testing and sensory measurements, are equally useful for perceived air quality assessment and provide important information about the acceptability of building materials for indoor use. The purpose of sensory assessment is to consider influence of indoor air quality to wellbeing [2].

Table 1. The individual materials and their combinations as floor and wall coverings

\begin{tabular}{|c|c|c|}
\hline Flooring covering & Walls/Ceiling & Combinations \\
\hline Oriented Strand Boards (OSB) & Painted gypsum boards & C1 \\
\hline HDF laminate (HDF) & Painted gypsum boards & C2 \\
\hline Polyamide carpet (PA) & Painted gypsum boards & C3 \\
\hline Polyvinylchloride (PVC) & Painted gypsum boards & C4 \\
\hline Cork (C) & Painted gypsum boards & C5 \\
\hline Terazzo (T) & Painted gypsum boards & C6 \\
\hline Cotton carpet (CC) & Painted gypsum boards & C7 \\
\hline Marmoleum (M) & Painted gypsum boards & C8 \\
\hline Wooden parquet (WP) & Painted gypsum boards & C9 \\
\hline LG Hi-macs (LG) & Painted gypsum boards & C10 \\
\hline Corian (Co) & Painted gypsum boards & C11 \\
\hline
\end{tabular}

Building materials and interior surfaces release a wide range of other VOCs which have been the subject of increasing. The emission can be a complex mixture of individual compounds, though a few may be dominant. A study of selected building materials identified different chemical species. Concentration of total volatile organic compounds (TVOC) expressed as concentration of toluene was measured with ppbRAE 3000, which is a photoionization detector (PID) with UV lamp. This device has a measuring range of $1 \mathrm{ppb}$ to $10000 \mathrm{ppm}$ and measurement accuracy $\pm 3 \%$. Three-second response time allows realtime monitoring with this instrument. Ultra-fast electronic nose called $\mathrm{zNose} \AA$, which is based on combination of gas chromatography and surface acoustic wave detector was used for sampling and analysis of individual VOCs. Manufacturer of this device specifies the standard deviation $<2 \%$. In the study, the recommended limit value $200 \mu \mathrm{g} / \mathrm{m}^{3}$ was used. The value represents the most critical approach to the indoor air quality assessment.

The exhaust air from test chamber was led through a diffuser for sensory assessments. An untrained sensory panel of 20 subjects assessed perceived air quality. Demand control material selection seems to be the most important approach in building design with respect to indoor air quality and environmental safety. Before the first assessment the panels were instructed how to use the scale and the exposure equipment. The responsible person of the experiment assessed each subject's attitude and motivation concerning to experiment as well as to their personal hygiene of the panel. There was no restriction on distribution of gender or smoking habits. The age ranged from 22 to 45 years and $30 \%$ of the subjects were smokers. The subjects indicated their immediate evaluation on continuous scale 
regarding acceptability of the air (from -1 clearly unacceptable to +1 clearly acceptable) from which the percentage of dissatisfied was estimated. The percentage of dissatisfied was estimated on the base of the relationship between percentage dissatisfied (PD) and mean acceptability. During the measurements, the test chambers were covered with aluminum sheets to hide the building products from the view of the sensory panels.

\section{Results}

Perceived air quality of material surfaces combination (C1) is represented by $95 \%$ percentage of dissatisfied. OSB boards flooring covering was presented by -0.67 odor acceptability and 3.2 odor intensity. Odor acceptability -0.62 and odor intensity 2.7 were evaluated in the case of this interior materials combination. Material surfaces combination (C2) perceived air quality is represented by the percentage of dissatisfied by $75 \%$. HDF laminate flooring covering was presented by -0.38 odor acceptability and 2.1 odor intensity. Odor acceptability -0.24 and odor intensity 1.6 were evaluated in the case of this interior materials combination. Painted gypsum boards for wall and ceiling covering were presented by 0.1 odor acceptability and 2 odor intensity. Perceived air quality of material surfaces combination $(\mathrm{C} 3)$ is represented by $60 \%$ percentage of dissatisfied. Odor acceptability 0.12 and odor intensity 1.62 were evaluated in the case of this interior materials combination, therefore this combination did not meet the criteria of perceived indoor air quality. Odor acceptability -0.25 and odor intensity 1.06 was achieved by polyamide carpet flooring covering. Perceived air quality of material surfaces combination (C4) is represented by $48 \%$ percentage of dissatisfied. Odor acceptability -0.07 and odor intensity 1.73 were evaluated in the case of this materials surfaces combination. Odor acceptability 0.08 and odor intensity 1.13 was achieved by PVC flooring covering. Material surfaces combination (C5) perceived air quality is represented by the percentage of dissatisfied by $18 \%$. Cork flooring covering was presented by 0,209 odor acceptability and 1.09 odor intensity. Odor acceptability 0,227 and odor intensity 0,818 were evaluated in the case of this interior materials combination. Perceived air quality of material surfaces combination (C6) is represented by $28 \%$ percentage of dissatisfied. Odor acceptability 0,155 and odor intensity 1.77 were evaluated in the case of this materials surfaces combination. Odor acceptability 0,146 and odor intensity 1.733 was achieved by Terazzo flooring covering. Material surfaces combination (C7) perceived air quality is represented by the percentage of dissatisfied by $23 \%$. Cotton carpet flooring covering was presented by 0.16 odor acceptability and 1.4 odor intensity. Odor acceptability 0.2 and odor intensity 1.33 were evaluated in the case of this interior materials combination. Perceived air quality of material surfaces combination (C8) is represented by $32 \%$ percentage of dissatisfied. Odor acceptability 0.127 and odor intensity 1.09 were evaluated in the case of this materials surfaces combination. Odor acceptability 0.036 and odor intensity 1.27 was achieved by Marmoleum flooring covering. Material surfaces combination (C9) perceived air quality is represented by $25 \%$ percentage of dissatisfied. Odor acceptability 0.07 and odor intensity 1.42 was achieved by wooden parquet flooring covering. Odor acceptability 0.18 and odor intensity 1.3 were evaluated in the case of this interior materials combination. Perceived air quality of material surfaces combination $(\mathrm{C} 10)$ is represented by $9 \%$ percentage of dissatisfied. Odor acceptability 0,391 and odor intensity 0.624 were evaluated in the case of this materials surfaces combination. Odor acceptability 0.345 and odor intensity 0,819 was achieved by LG-Hi macs flooring covering. Material surfaces combination (C11) perceived air quality is represented by the percentage of dissatisfied by $7 \%$. Corian flooring covering was presented by 0,382 odor acceptability and 0.727 odor intensity. Odor acceptability 0.436 and odor intensity 0.545 were evaluated in the case of this interior materials 
combination. Perceived air quality of material surface combinations (C1-C11) estimated by percentage of dissatisfied are shown in the Table 2.

OSB boards as flooring covering individually achieved TVOC emissions value 40.3 $\mu \mathrm{g} / \mathrm{m}^{3}$ and for material combination $(\mathrm{C} 1)$ represent value $22.5 \mu \mathrm{g} / \mathrm{m}^{3}$. Measured TVOCs emissions concentration of material surfaces combination (C2) represent value $28.7 \mu \mathrm{g} / \mathrm{m}^{3}$ and HDF laminate flooring covering represent value $21.5 \mu \mathrm{g} / \mathrm{m}^{3}$. Polyamide carpet as flooring covering achieved TVOC emissions value $9.7 \mu \mathrm{g} / \mathrm{m}^{3}$ and material combination (C3) represent value $11.1 \mu \mathrm{g} / \mathrm{m}^{3}$. Measured TVOCs emissions concentration of material surfaces combination (C4) represent value $52.3 \mu \mathrm{g} / \mathrm{m}^{3}$ and PVC flooring covering represent value $44.8 \mu \mathrm{g} / \mathrm{m}^{3}$. Cork as flooring covering achieved TVOC emissions value $17.2 \mu \mathrm{g} / \mathrm{m}^{3}$ and material combination (C5) represent value $18.3 \mu \mathrm{g} / \mathrm{m}^{3}$. Measured TVOCs emissions concentration of material surfaces combination (C6) represent value $8.2 \mu \mathrm{g} / \mathrm{m}^{3}$ and Terazzo flooring covering represent value $6.1 \mu \mathrm{g} / \mathrm{m}^{3}$. Cotton carpet as flooring covering achieved TVOC emissions value $8.7 \mu \mathrm{g} / \mathrm{m}^{3}$ and material combination (C7) represent value $9.5 \mu \mathrm{g} / \mathrm{m}^{3}$. Measured TVOCs emissions concentration of material surfaces combination (C8) represent value $6.8 \mu \mathrm{g} / \mathrm{m}^{3}$ and Marmoleum flooring covering represent value $7.9 \mu \mathrm{g} / \mathrm{m}^{3}$. Wooden parquet as flooring covering achieved TVOC emissions value $7.5 \mu \mathrm{g} / \mathrm{m}^{3}$ and material combination (C9) represent value $9.7 \mu \mathrm{g} / \mathrm{m}^{3}$. The measured TVOCs emissions concentration of material surfaces combination (C10) represent value $7.3 \mu \mathrm{g} / \mathrm{m}^{3}$ and LG-Hi macs flooring covering represent value $3.2 \mu \mathrm{g} / \mathrm{m}^{3}$. Corian as flooring covering achieved TVOC emissions value $2.5 \mu \mathrm{g} / \mathrm{m}^{3}$ and material combination $(\mathrm{C} 11)$ represent value 5.9 $\mu \mathrm{g} / \mathrm{m}^{3}$. In terms of TVOCs concentration (sorption effect) the material combinations with Marmoleum and OSB boards were achieved improved results. Worse results were achieved in the case of material combination with HDF laminate and polyamide carpet flooring covering. The sorption effect of odor acceptability, odor intensity and TVOCs concentration are interpreted in the followed figures (Figure 1-3).

Table 2. The individual materials and their combinations

\begin{tabular}{|c|c|c|c|c|c|c|c|c|}
\hline materials & OA & OI & $\begin{array}{c}\text { TVOCs } \\
\left(\boldsymbol{\mu g} / \mathbf{m}^{3}\right)\end{array}$ & $\mathbf{c o m b i}$ & $\mathbf{O A}$ & $\mathbf{O I}$ & $\begin{array}{c}\text { TVOCs } \\
(\boldsymbol{\mu g} / \mathbf{m})\end{array}$ & $\begin{array}{c}\text { PD } \\
{[\%]}\end{array}$ \\
\hline OSB & -0.67 & 3.2 & 40.3 & $\mathrm{C} 1$ & -0.62 & 2.7 & 22.5 & 95 \\
\hline HDF & -0.38 & 2.1 & 21.5 & $\mathrm{C} 2$ & -0.24 & 1.6 & 28.7 & 75 \\
\hline PA & -0.25 & 1.06 & 9.70 & $\mathrm{C} 3$ & -0.12 & 1.62 & 11.1 & 60 \\
\hline PVC & 0.08 & 1.13 & 44.8 & $\mathrm{C} 4$ & -0.07 & 1.73 & 52.3 & 48 \\
\hline C & 0.209 & 1.09 & 17.2 & $\mathrm{C} 5$ & 0.227 & 0.818 & 18.3 & 18 \\
\hline T & 0.146 & 1.733 & 6.10 & $\mathrm{C} 6$ & 0.155 & 1.77 & 8.2 & 28 \\
\hline CC & 0.16 & 1.4 & 8.70 & $\mathrm{C} 7$ & 0.2 & 1.33 & 9.5 & 23 \\
\hline M & 0.036 & 1.27 & 7.90 & $\mathrm{C} 8$ & 0.127 & 1.09 & 6.8 & 32 \\
\hline WP & $0 . .7$ & 1.42 & 7.50 & $\mathrm{C} 9$ & 0.18 & 1.3 & 9.7 & 25 \\
\hline LG & 0.345 & 0.819 & 3.20 & $\mathrm{C} 10$ & 0.391 & 0.624 & 7.3 & 9 \\
\hline Co & 0.382 & 0.727 & 2.50 & $\mathrm{C} 11$ & 0.436 & 0.545 & 5.9 & 7 \\
\hline PGB & 0.1 & 2 & 18.1 & - & - & - & & - \\
\hline
\end{tabular}




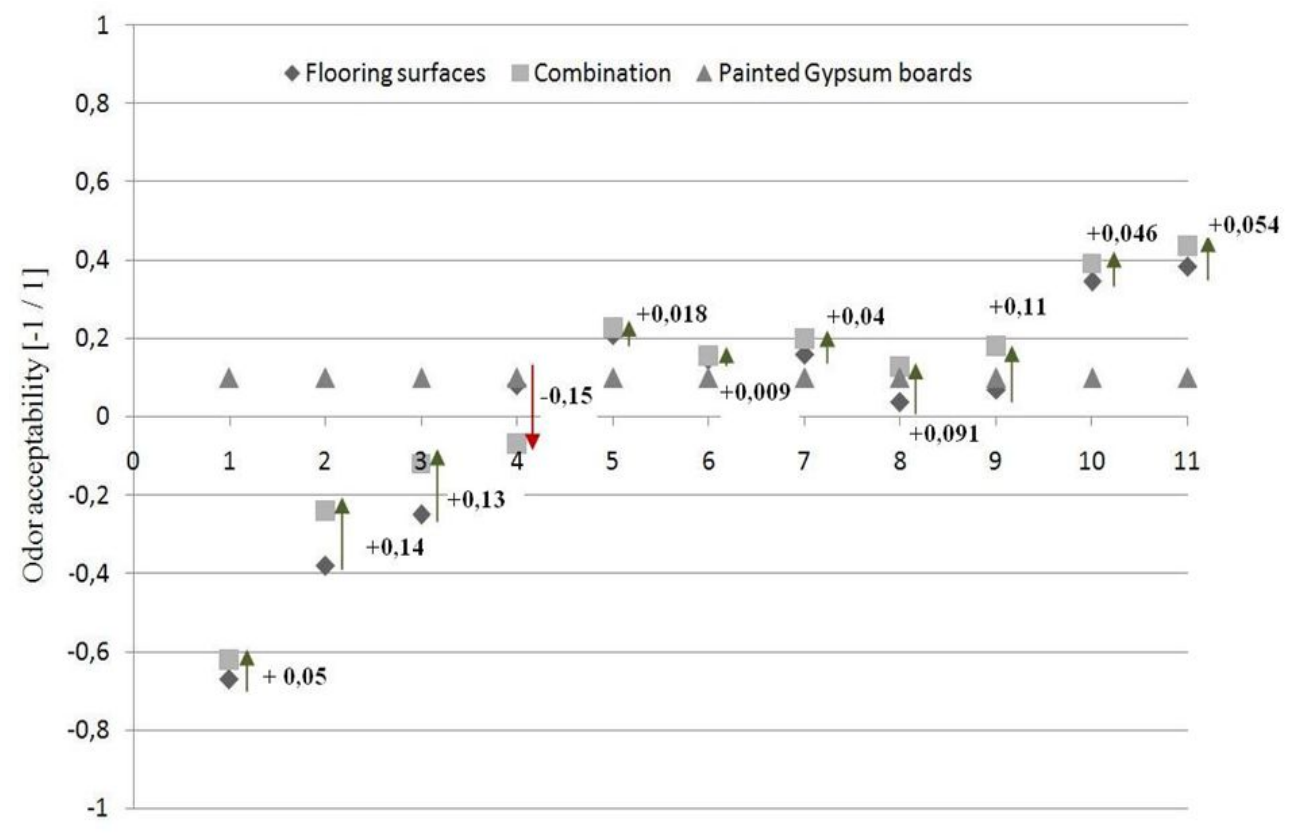

Fig. 1. Odor acceptability sorption effect

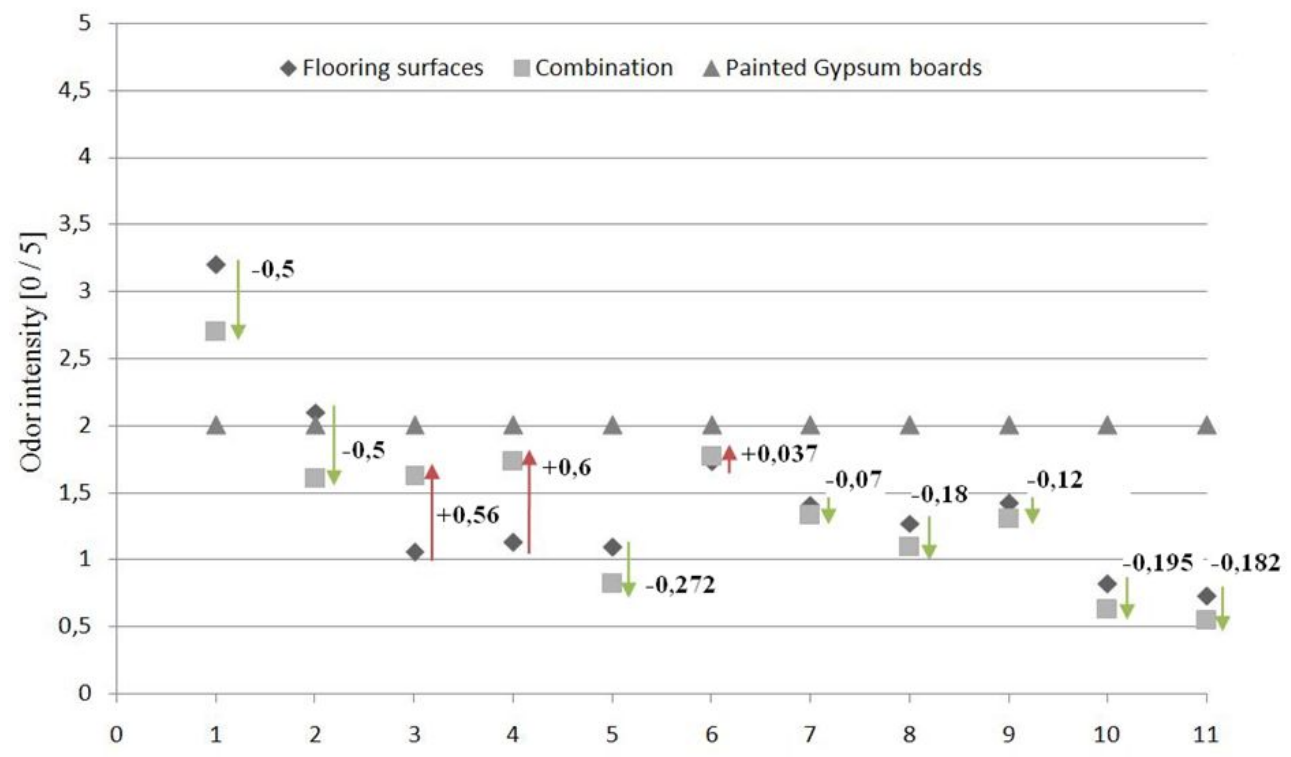

Fig. 2. Odor intensity sorption effect 
In terms of odor acceptability (sorption effect) the material combinations with HDF laminate and polyamide carpet were achieved improved results. Worse result was achieved in the case of material combination with PVC flooring covering.

In terms of odor intensity(sorption effect) the material combinations with HDF laminate and OSB boards were achieved improved results. Worse results were achieved in the case of material combination with PVC and polyamide carpet flooring covering.

In terms of TVOCs concentration (sorption effect) the material combinations with Marmoleum and OSB boards were achieved improved results. Worse results were achieved in the case of material combination with HDF laminate and polyamide carpet flooring covering.

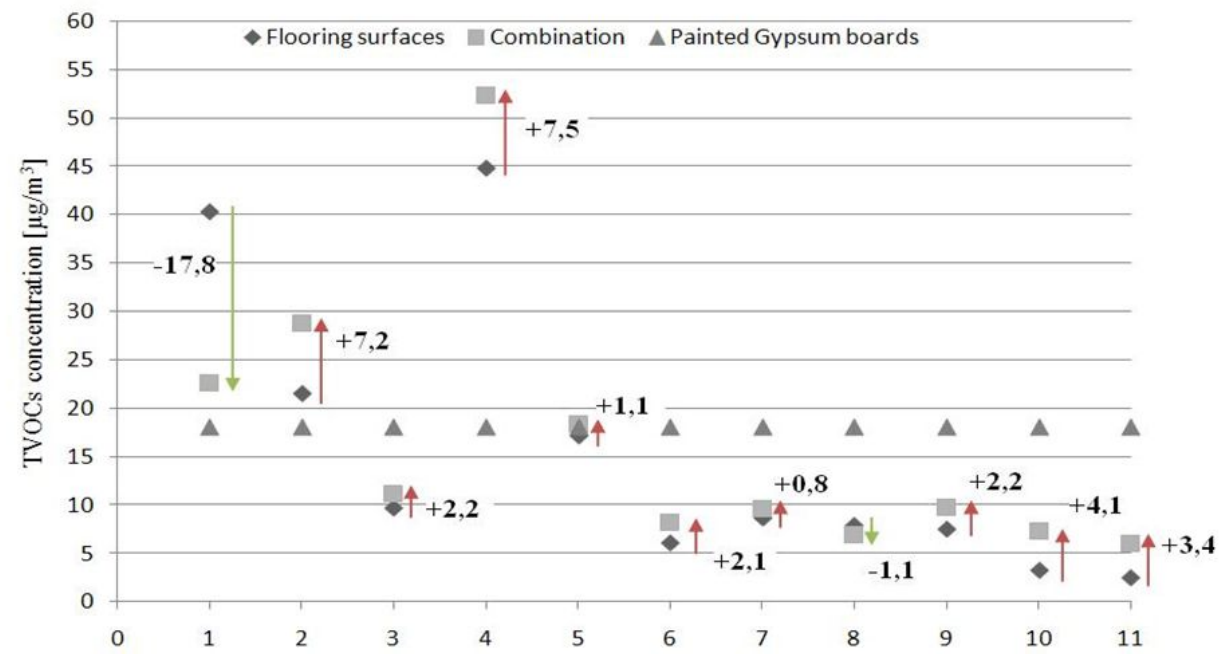

Fig. 3. TVOCs concentration sorption effect

\section{Discussion}

The selection of the materials and their combinations is strongly based on the intuitive assumption that they will reduce exposure to occupants to potentially dangerous or harmful chemicals. This is the paper that examines concentration exposure of VOC and odor perceiving in indoor air of interior materials typically used in office buildings.

The results in graphs and tables are ranked from worst to the most favorable. In most cases we can see similar results of individual material combinations by each criterion of the evaluation. Sorption effect constitutes an important aspect of indoor air quality results. In any cases, we can see the difference between the flooring materials TVOCs concentrations results and TVOCs concentration results of their combination. Most acceptable results in each criterion (odor acceptability, odor intensity and TVOCs concentration) were achieved in the case of material combination with Corian and LG-Hi macs flooring covering. Acceptable results in each criterion were achieved in the case of material combination with cotton carpet, marmoleum and wooden parquet flooring covering. Unacceptable results in each criterion were achieved in the case of material combination with OSB boards, HDF 
laminate, polyamide carpet and PVC flooring covering. Most material combination achieved the similar assessment results in each criterion.

\section{Conclusions}

Sorption on the surface of individual materials constitutes an important role in evaluating of the Indoor air quality. Only in the case of material combination with PVC as flooring material we can see unacceptable and negative influence of the sorption effect in each criterion. The case of OSB boards and gypsum board combination showed better measured values of TVOCs concentration than the individual materials themselves. Conversely, in the case of Corian and LG-Hi macs combination the materials themselves showed better measured values than their material combinations. It is demonstrated that in the cases of materials combinations with positive TVOCs concentrations may cause adverse sorption effect and conversely, in the case of materials combination with negative TVOCs concentrations can lead to positive sorption effect. The questioner mains whether it is more important actual TVOCs concentration or positive impact of sorption effect in longer term.

The interior surface materials emissions and odors were investigated in glass test chamber. The aimed material combinations impact to air quality was reported and positive effects of selected material combinations were recognized. The significant impact of indoor surface material on perceived air quality as well as generally the positive interaction effect was confirmed. Both, parallel used methods, chemical testing and sensory measurements, are equally useful for perceived air quality assessment and provide important information about the acceptability of indoor materials. The main purpose of sensory assessment is to consider and mainly respect the influence of indoor air quality to human wellbeing. In order to guarantee acceptable indoor air quality the identification of all important indoor odor sources is required. The measure of indoor air pollution decreasing is the effective material control. Demand control material selection seems to be the most important approach in building design with respect to perceived indoor air quality and green building concept.

The author is grateful to national grant agency for supporting the indoor air sciences research projects.

\section{References}

1. I. Juhasova Senitkova, MATEC Web of Conferences, 93, 03001 (2017)

2. I. Senitkova, Material Science Engineering C, 36, 6 (2014)

3. I. Senitkova, T. Tomcik, Advanced Science Letters, 19, 9 (2013)

4. C. Howard-Reed, S. J. Nabinger, Research Triangle Park NC: EPA/AWMA, 6 (2006)

5. W. Horn, O. Wilke, K. Wiegner, final report. BAM. Berlin: Federal Institute for Materials Research and Testing (2010)

6. F.Haghighat, L.Bellis, Building and Environment, 33, 261-277 (1998) 